\section{Laughter and Balance}

\section{A Letter to a Junior Resident}

William M. Tierney, MD
$I^{\mathrm{r}}$ heard you laugh. Amid the banter, you discussed your "neat case," describing his presentation, the difficulties we faced, and our ultimate "success" in resuscitating him. You sounded lighthearted, and I almost said something. But I feared I was misinterpreting your laughter or that I might seem confrontational. I didn't want you to be embarrassed and angry and not hear the message, so I said nothing. But I wanted to.

Why did your laughter pain me so? I understand the healing power of laughter and its ability to create a safe place within which we can avoid the harsh reality of our emotions. Yet your laughter echoes in my ears along with other voices: the young wife as she trembled and asked me whether he would survive; the younger brother's sobbing; the father's pale silence; his mother's calm voice as she comforted her family with the strength of steel; and finally, 2 days later, the ward resident telling me that our young patient was brain-dead and that his organs were being "harvested." (How I hate that word!)

One of the most rewarding aspects of our profession is the opportunity to participate in other people's lives. With incredible trust and disarming openness, our patients share their pain, fears, trauma, and triumphs. Yet the emotional cost we bear in sharing such knowledge can be devastating, at times career-ending. Early in your career, you must learn how to deal with the suffering of your patients and their families, friends, and lovers. Unfortunately, most house officers feel awkward, intrusive, and unsure of themselves. (I certainly did.) We hide our feelings behind walls of laughter and banter, or worse, cynicism. Dealing with the emotional suffering of our patients is painful, and we tend to avoid such situations. Yet with effort and guidance most caring physicians can master this aspect of their art, comfort their patients at their most vulnerable times, and deepen their own personal experiences.

It is much harder, however, to deal with our own mistakes and failures. Being fallible humans, physicians will make mistakes, sometimes in their judgments and sometimes in their actions, and their patients may suffer as a result. Even when everything is done correctly, we may

Received from the Wishard Memorial Hospital, and Indiana University School of Medicine, Regenstrief Institute for Health Care, Richard L. Roudebush Veterans Affairs Medical Center, Indianapolis, Ind.

Address correspondence and reprint requests to Dr. Tierney: 6th Floor, RHC, 1001 West Tenth Street, Indianapolis, IN 46202. fail to achieve the expected outcomes. Dealing with these failures and the devastating effect they can have on patients and families is a hurdle that all clinicians must overcome in order to trust themselves and be trusted by their patients. Self-incrimination will often follow such failures, as it probably should: I don't think I would trust a physician who doesn't question her abilities when the results of her care don't meet with her expectations.

With this in mind, I am struck by the disparity of the responses you and I had to our recent mutual failure. I have practiced medicine for 20 years, yet when I heard that this handsome young man with the athlete's body and the lovely family had died from his asthma, I questioned my skills and beat myself up over our inability to save him. I even insisted that this "case" be presented at Morbidity and Mortality Conference to examine and criticize our performance. (Remember? You and I both failed to intubate him, later comforting ourselves knowing that two EMTs and their supervisor had also been unable to intubate him in the field, presumably because of his short, muscular neck and aberrant tracheal anatomy.) I retraced our steps again and again, questioning every move. Should I have attempted intubation sooner, or longer? Should I have pushed the fumbling, inexperienced surgical resident out of the way and performed the tracheostomy myself?

I have no answers. We simply failed, a young man died, and I had trouble dealing with it. This was my mental state when I overheard your laughter and discussion of your "neat case."

As time has passed, my pain has lessened. I have returned to the ER and have not been paralyzed. I have learned from this "case" and will do better next time. But what about you? What have you learned? Was your laughter sheltering you from deeper feelings of pain and inadequacy? How are you doing now? I worry about you and all young physicians, having seen events such as this devastate otherwise promising careers, driving good clinicians away from clinical medicine or making them callous and cynical.

I didn't know how to say this to you when I heard you laughing. I did not want to confront you without understanding the deeper feelings that might be lurking behind your laughter. How did you handle the emotional side of this case? How will it help you avoid future mistakes and help grieving families? It is asking a lot of you to dissect such experiences, but no less will do. If we are to be good doctors, we cannot avoid suffering; we must meet it headon, experience it, and know it. But we must be careful: if we get too close, we can be burned and become so scarred 
that we can no longer practice. If our distance is too great, we may lack the sensitivity required to understand and treat our patients' pain. Being courageous and maintaining balance are the keys to examining and surviving our emotions when confronted with our fallibility and the pain and suffering of others.

But how can one critically examine such experiences and remain a confident, capable clinician? There are no easy answers. We each must find our own way to work out such emotions. Some play music, some lock themselves in a bathroom and cry, some shout or pound pillows until the feathers fly, and others like me write or sweat it out.

To deal with the emotions that threatened to overwhelm me as a resident, I resorted to the road and the pen. Despite long hours of work and little sleep, I would go on extended, solitary runs along straight, flat country roads. On these runs, I would push my physical pain to levels that matched my mental anguish. Afterwards, I would be physically exhausted but emotionally recharged. At other times, I would write about my pain, doubts, and fears. It seemed that by describing and recording my distress, I could lock it in a box to which only I had the key.
I have also found solace in the thoughts of other writers. For example, in his book, Young Men and Fire, Norman MacLean wrote:

In a journey of compassion what we have ultimately as our guide is whatever understanding we have gained along the way of ourselves and others, chiefly those close to us, so close to us that we have lived daily in their sufferings. From here on, then, in the blinding smoke it is no longer a "seeing world" but a "feeling world"-the real pain of others and our compassion for them.

You and I must continue to practice in the face of suffering and the knowledge of our individual fallibility. We each must gauge the distance that allows us to practice compassionate medicine. We must not be consumed by our patients' suffering, but we must not become inured to it, either. For who would want to be led through the circles of our medical Hell, through corridors of suffering and death, by a guide who cannot feel, appreciate, and ease our pain?

The author thanks Amy Justice for her encouragement and suggestions and Chris Callahan for criticisms of earlier versions of this manuscript. 